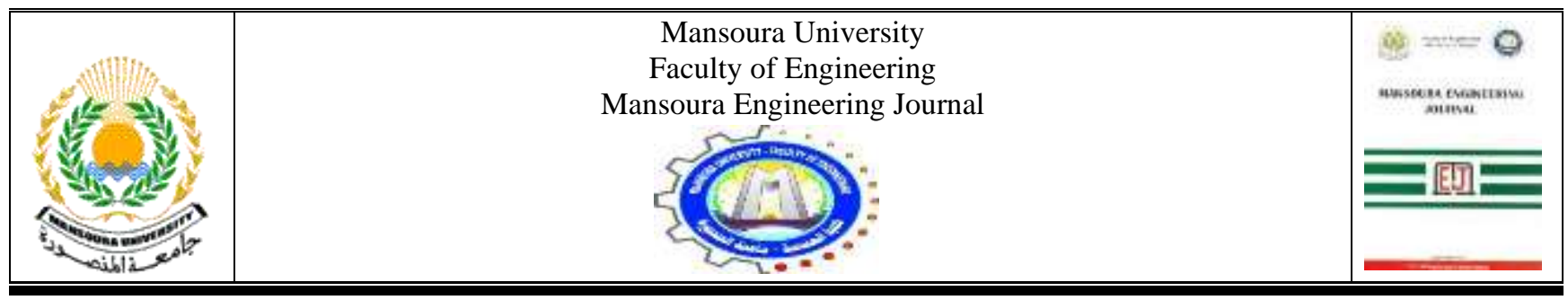

\title{
Development of Composites from Polyester Reinforced with Rice Straw and with Hybrid Rice Straw/Glass Fiber

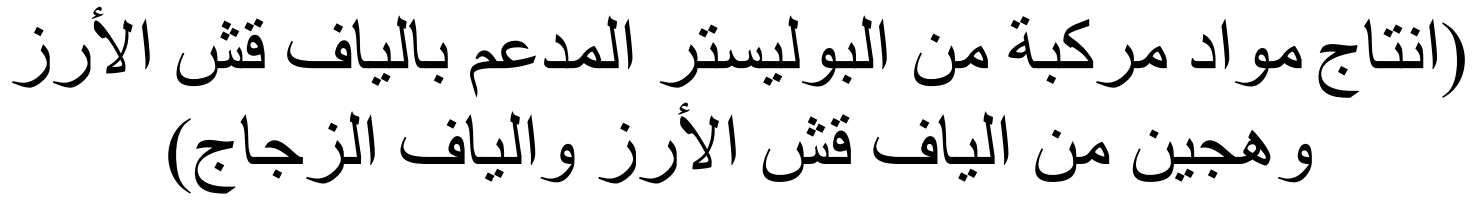

Soliman S. Ali-Eldin, Sara M. Abd El Moezz, M. Megahed and W. S. Abdalla

\begin{abstract}
KEYWORDS:
Rice straw mat; polymer

composites; hybrid

composites; mechanical

properties.
\end{abstract}

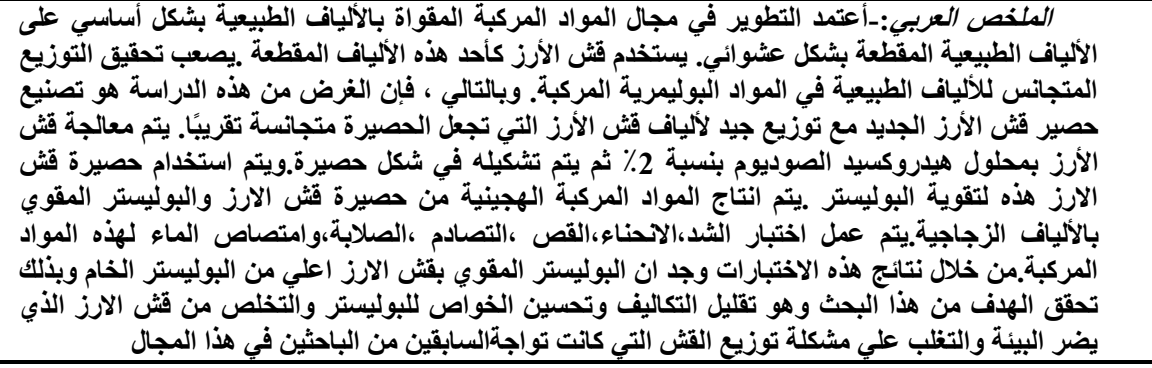

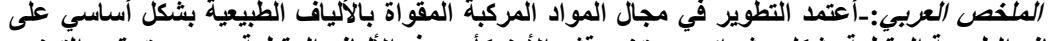

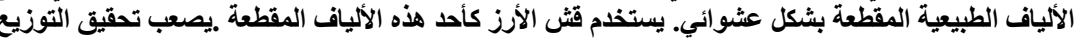

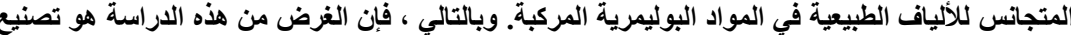

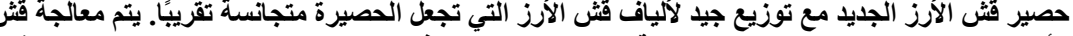

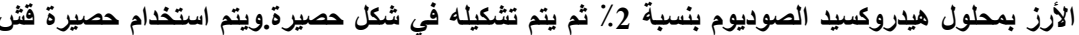

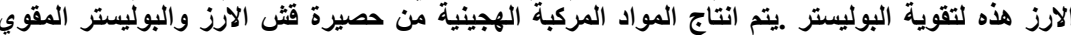

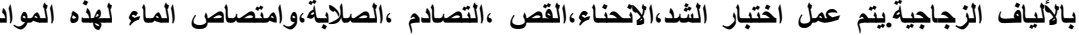

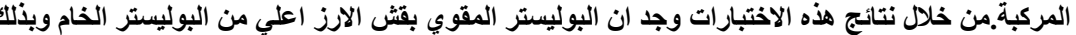
يضر البيئة والتظلب علي مشكلة توزيع القش التي كانت تواجة|لسابقين من الباحثين في هذا المجال

\begin{abstract}
Developments in the area of natural fiber reinforced composites have based mainly on random discontinuous natural fibers. Rice straw is used as one of these discontinuous fibers. Uniform distribution of discontinuous natural fibers in composite laminates is difficult to be attained. Consequently, the purpose of this study is to develop new rice straw mat with a good distribution of rice straw fibers that reduces the discontinuity and make the mat nearly homogeneous. The rice straws are treated with $2 \mathrm{wt} \%$ sodium hydroxide solution then formed into a mat. This new rice straw mat is used to reinforce a polyester matrix. Hybrid composites are produced from rice straw mat and
\end{abstract}

Received: 21 May, 2019 - revised: 30 October, 2019 - accepted: 3 November, 2019

Soliman S. Ali-Eldin, Department of Mechanical Design and Production Engineering, Faculty of Engineering, Zagazig University

Sara M. Abd El Moezz, Researcher at Faculty of Engineering - Zagazig University-Production Engineering and Mechanical Design Department

M. Megahed, Department of Mechanical Design and Production Engineering, Faculty of Engineering, Zagazig University,

W. S. Abdalla, Department of Mechanical Design and Production Engineering, Faculty of Engineering, Zagazig University; P.O. Box 44519, Zagazig, Egypt. glass fiber reinforced polyester. Tensile, flexural, shear, impact, hardness, and water absorption behavior of these natural composites are investigated. Rice straw composites have higher mechanical properties than pure polyester. Hybridization enhances the mechanical properties over rice straw composites. The fracture surfaces of natural fiber reinforced polyester composites are examined by scanning electron microscope.

\section{INTRODUCTION}

$\mathrm{N}$ ATURAL fiber composites can replace environmentally harmful synthetic composites which help to control the problems of pollution. Also, the main advantages of natural fibers are their low cost [2], [3], [4]. The other advantages of natural fibers include high stiffness and specific modulus, lower health risk, reducing tool wear, enhanced energy recovery, reduced dermal and respiratory irritation. All these advantages made them be widely used for many applications over the recent years [5], [6]. Lightweight natural fiber composites lead to improve fuel efficiency in auto applications [7]. Consequently, such notable advantages of these composites improve their commercial and research potentials [8]. Nevertheless, the 
main problem in using natural fiber as reinforcement in polymer is poor adhesion between polymer matrix and natural fiber [9]. Abdelmouleh et al. [2] reported that as a cause of low interaction of fibers with matrix, the load transfer from matrix into natural fiber is bad. Thus, natural fiber surface must be modified to decrease polarity of fiber and so compatibility at interface region is improved [10]. Yan et al. [11] improved the mechanical properties of natural fiber composites by using the alkali treatment of flax fiber. They used $5 \%$ sodium hydroxide $(\mathrm{NaOH})$ for $30 \mathrm{~min}$, and then made the flax epoxy composite. A large improvement was observed in tensile and flexural strength beside some improvement in transverse strength. Furthermore, coir fibers were treated with $\mathrm{NaOH}$ for 10 days with $2 \%, 4 \%, 6 \%, 8 \%$, and $10 \%$ concentration. The mechanical properties of coir composites, internal bond and modulus of rupture, improved due to chemical composition and surface modification [12]. Besides, the shortcomings of natural fibers are their high moisture content, inconsistency on their properties, flammability and uneven dispersion in products, particular short fiber. These shortcomings affect the quality of resultant composites [8].

Rice is in the second rank in world's largest cereal harvest. Rice straw is found with huge amounts much more than that of rice husk. Making use of it will have a more substantial impact [13].

Hybrid composites are manufactured to obtain tailored properties that are difficult to attain with single fiber. The researchers studied a combination of natural/natural or natural/synthetic fiber-based hybrid composites. These combinations have certain advantages over individual fiberreinforced. Hybrid fiber reinforced composites is suitable for low cost applications and this type of materials are very common in engineering market as construction and automotive industries [1]. Fabricating a hybrid composite gains the advantages that one type of fiber can complement that are lacking in other fiber. Hybridization shows greater tensile strength as compared to individual kind of natural fibers. Hybridization of natural fiber by another natural fiber reinforcement doesn't yield superior mechanical properties as when hybridized with glass fiber[2]. Several researches study the effect of hybridization between natural and glass fibers embedded in polymer matrix. Reinforcing E-glass fiber into sisal polypropylene composites improved tensile and bending properties with no effect on tensile and flexural modulus. Moreover, adding sisal fiber with glass fiber enhances thermal properties and water barrier of the hybrid composites [3]. Also, reinforcing with hemp fiber and glass fiber hybrid composites increases the flexural, impact and water barrier properties [4]. Similarly, Ashik et al. [5] found that incorporation of coconut coir and E-glass fiber can enhance strength and used as an alternate fibers for glass fiber in fiber reinforced composites.Also, tensile, bending, shear, impact and water barrier properties are increased due to the incorporation of glass fiber along with palmyra fiber in polyester matrix [24]. Fiber dispersion is identified as the main factor affecting the properties of short fiber composites and a big challenge for natural fiber composites, which commonly have hydrophilic fibers and hydrophobic matrix [25]. Use of longer fibers can further increase their tendency to agglomerate. The current work aims to develop new natural fiber composite systems with good dispersion of rice straw fibers. New mat form of with good distributed rice straw fibers is developed and reinforced polyester matrix. Hybrid composites of rice straw mat/glass fiber are manufactured. The mechanical behavior of these new composite materials is investigated to explore the possibility of utilizing it in different applications as an alternative to conventional materials.

\section{EXPERIMENTAL WORK}

\section{A. Materials and manufacturing}

The natural cellulose fibers used in this study are rice straw. Rice straw is obtained from Mansoura, Egypt. Rice straw (RS) is chosen as it represents agricultural wastes from Egyptian local field collected at the end of the harvest time [6]. Another reinforcement used is random E-glass fiber with a diameter of $17 \mu \mathrm{m}$. The matrix is polyester $(\mathrm{P})$.

Contaminants are removed and rice straws are cut into 5 cm length as shown in Fig. 1 (a). These rice straws are washed in running water. Rice straws are soaked in 2.0 wt $\% \mathrm{NaOH}$ for $48 \mathrm{hrs}$. Treating natural fiber with $\mathrm{NaOH}$ leads to fibrillation and causes the breakdown of bundles of natural fibers into smaller fibers. So, this develops a rough surface topography that results in better fiber-matrix interface adhesion and an increase in mechanical properties. Moreover, this treatment allows better fiber wetting [7]. The average diameter of the rice straw fiber at the end of the treatment varies from $0.9 \mathrm{~mm}$ to $3 \mathrm{~mm}$ according to the place that is taken from, whether the stem, leaves, or spikelet. The length of rice straw is $4 \mathrm{~mm}$. This solution is boiled for two hours until the straws became soft. The boiled rice straws are washed thoroughly with water and formed into balls. The balled rice straws are crushed with a wooden mallet or a pestle as shown in Fig. 1 (b). Then, the rice straws is screened on double screen mould, 50 mesh screen is placed on top of a 100 mesh screen, with the aid of running water under high water pressure as shown in Fig. 1 (c). By shaking the mould to get rid of the water, most of water comes out throughout the screen. The mash is then pressed with a roller to remove the water and to distribute the straws uniformly as indicated in Fig. 1 (d). The rice straw sheet is dried by hanging in open air and under sunray. Figure 1 (e) and (f) show the rice straw sheet after drying in the mould and the final form of the developed rice straws mat, respectively. This produced rice straws mat is $388 \mathrm{~g} / \mathrm{m}^{2}$. The fiber volume fraction of RS in $\mathrm{RS} /$ polyester (VRS) is $40 \%$ [8]. The fiber volume fraction of glass fiber in glass fiber/polyester (VGF) is $20 \%$ [9]. However, Table 1 shows chemical characterization revealed the proportion of each component of the newly developed rice straw mat. Oxygen and carbon are the major two constituents in the developed rice straws mat. Scanning electron microscope (SEM) for the developed rice straws mat is shown in Figure 2. This figure shows a good distribution of rice straw which indicates homogeneity in the manufactured new rice straw sheets. 


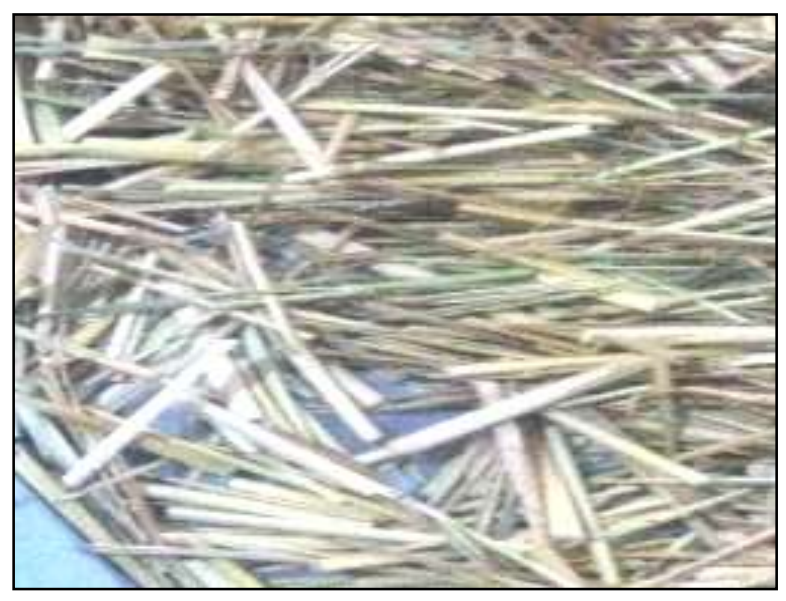

$a$

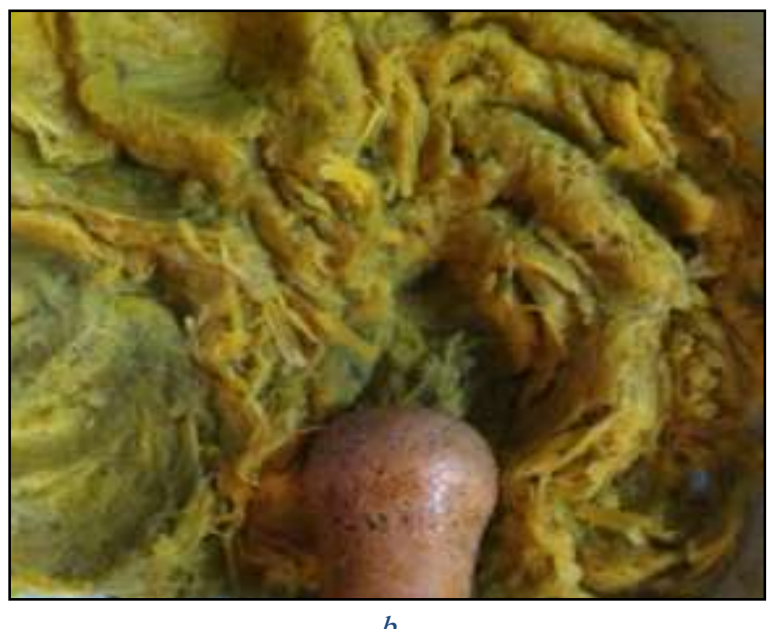

$b$

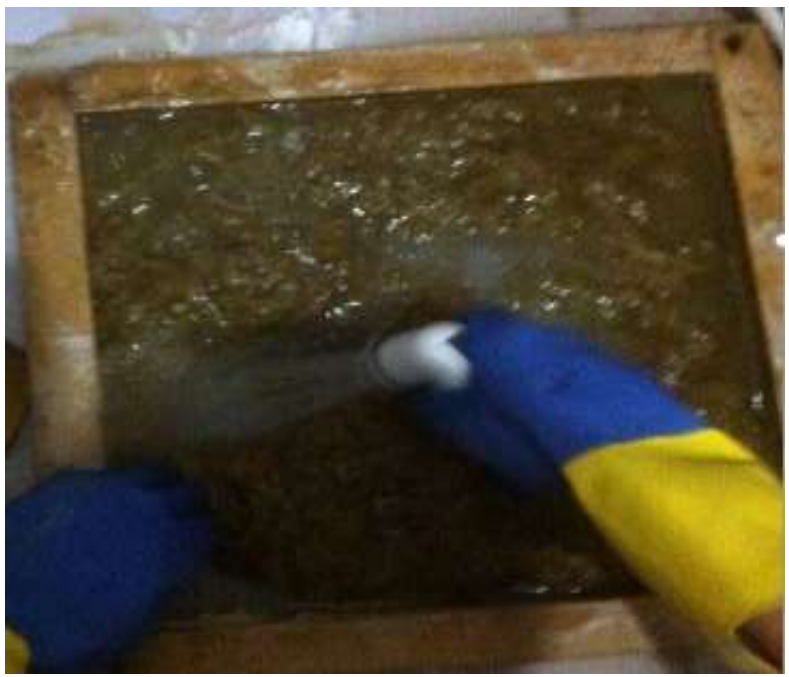

$c$

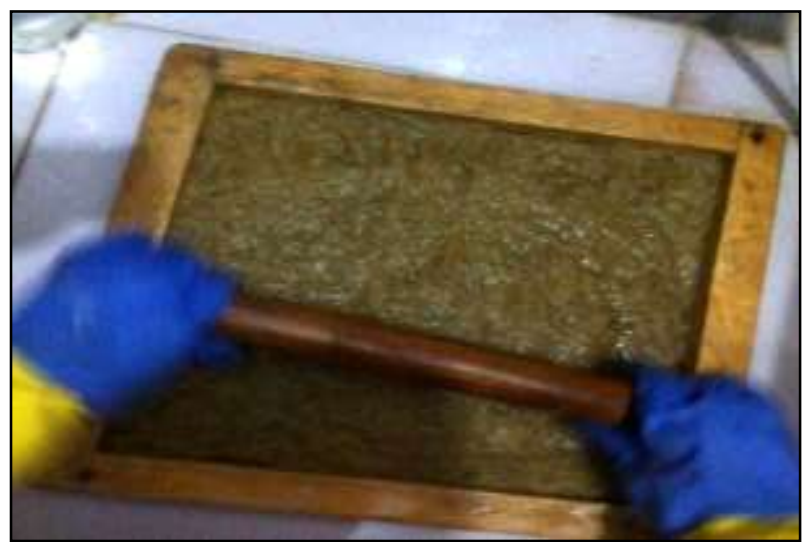

$d$
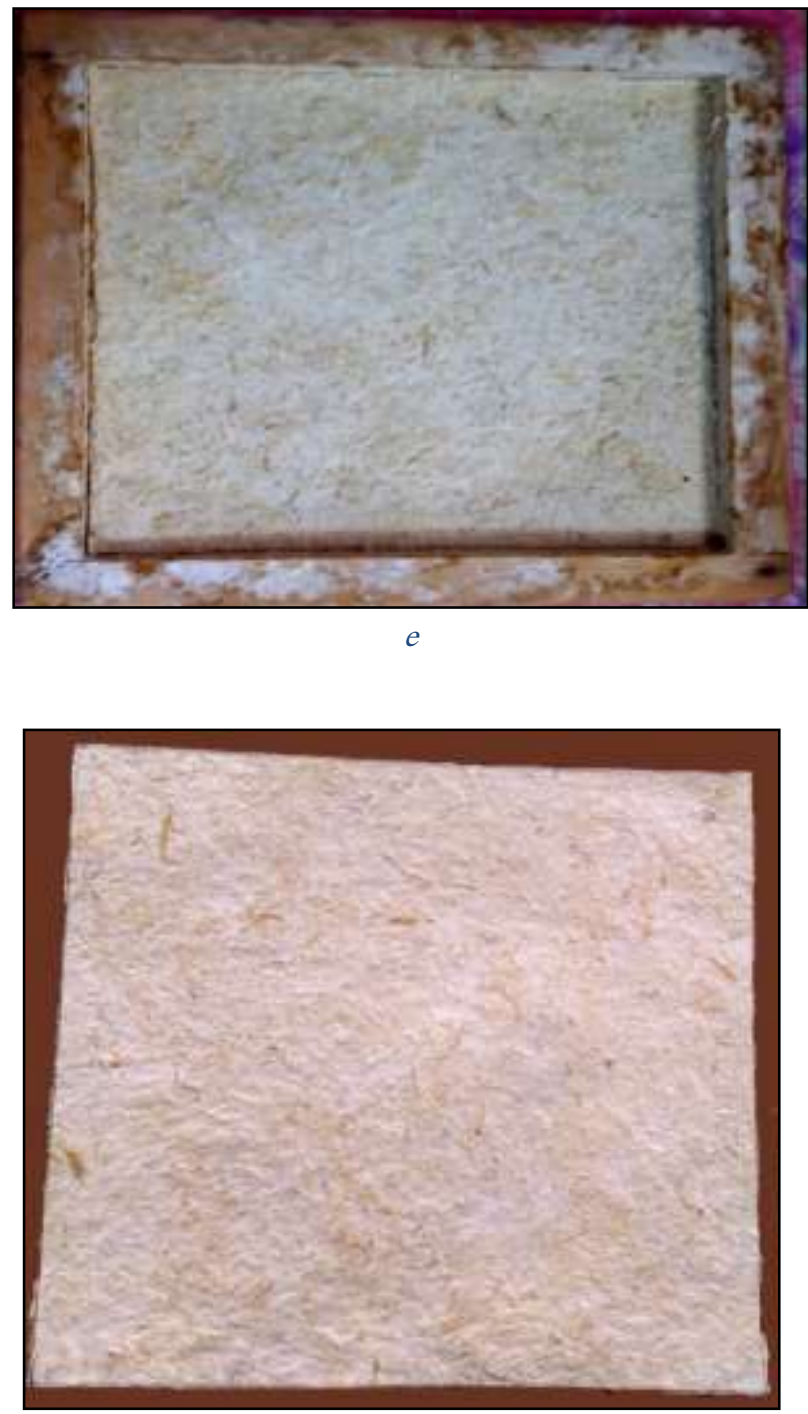

$f$

Fig. 1. Development of rice straws mat processes. 
TABLE 1. CHEMICAL COMPOSITION OF DEVELOPED RICE STRAW

\begin{tabular}{l||l} 
Constituent & Content \% \\
\hline $\mathrm{C}$ & 41.2 \\
\hline $\mathrm{O}$ & 45.8 \\
\hline $\mathrm{Si}$ & 0.45 \\
\hline $\mathrm{P}$ & 0.009 \\
\hline $\mathrm{Ca}$ & 0.57 \\
\hline $\mathrm{Mg}$ & 0.4 \\
\hline $\mathrm{Ash}$ & 5.5
\end{tabular}

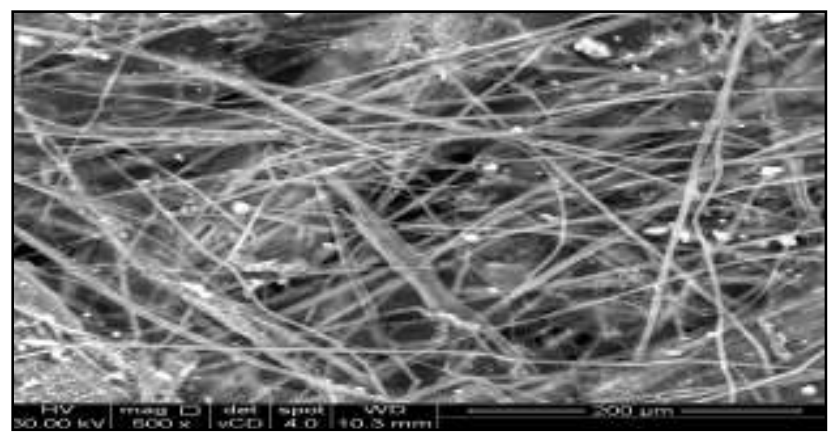

Fig. 2. SEM for the developed rice straws mat.

Three different composite laminates are manufactured using Hand Lay-Up technique and compression molding.

The composition of manufactured fiber composites is shown in Table 2. Pure RS composites are manufactured from new developed rice straw mat. Hybrid composites are manufactured from rice straw mat as a natural fiber and glass fiber (GF) as synthetic fiber. A laminate of chopped glass fiber is manufactured to show the difference between natural and synthetic composites and also to detect the effect of hybridization of both types of fibers. Both hybrid GF/RS/polyester and GF/polyester composites are formed from five plies of fiber mat impregnated with Polyester matrix. In hybrid composites polyester reinforced with two plies of RS mat and three plies of glass fiber reinforcement mats. Glass fiber layers are placed on the outer surfaces as manufacturing of GF layers at the ends that give good mechanical strength [10].

\section{A. Measurement and characterization}

\section{Mechanical properties}

\section{a) Tensile test}

Tensile tests are conducted according to ASTM D3039. The tensile tests are performed with a universal testing machine, Jinan Test Machine WDW $100 \mathrm{kN}$. This test has occurred with constant cross-head rate $2 \mathrm{~mm} / \mathrm{min}$ for all specimens and at room temperature. Stress-strain curve is recorded automatically by a computer data acquisition system. Five specimens are tested for each type of composite samples.

\begin{tabular}{c|c|c|cc} 
Designation & Description & $\begin{array}{c}\mathrm{RS} \\
\left(\mathrm{M}_{\mathrm{f}}\right. \\
\%)\end{array}$ & $\begin{array}{c}\mathrm{GF} \\
\left(\mathrm{M}_{\mathrm{f}}\right. \\
\%)\end{array}$ & $\begin{array}{c}\mathrm{P} \\
\left(\mathrm{M}_{\mathrm{f}}\right. \\
\%)\end{array}$ \\
\hline$P$ & Pure Polyes ter & 0 & 0 & 100 \\
\hline$R S$ & $\begin{array}{c}\text { Rice straw } \\
\text { reinforced } \\
\text { polyester matrix }\end{array}$ & 24.35 & 0 & 75.7 \\
\hline GRGRG & $\begin{array}{c}\text { GF/RS/GF/RS/GF } \\
\text { reinforced } \\
\text { polyester }\end{array}$ & 13.6 & 13.1 & 73.3 \\
\hline$G F$ & $\begin{array}{c}5 \text { layers of glass } \\
\text { fber reinforced } \\
\text { polyester }\end{array}$ & 0 & 32.53 & 67.47
\end{tabular}

TABLE. 2. Composition and designation of mamu factured fiber composites.

\section{b) Three-point bending test}

The flexural strength is studied using three-point bending test and is carried out by the same universal testing machine, according to ASTM standard D-790. Flexural strength of the composite material, $\sigma_{f}$, is calculated as follows [11]:

$$
\sigma_{f}=\frac{3 * F * L}{2 * w * t^{2}}
$$

where $\mathrm{F}$ is the applied load $(\mathrm{N})$; $\mathrm{L}$ is support span in $\mathrm{mm}$; w and $\mathrm{t}$ are the width and the thickness of the sample in $\mathrm{mm}$, respectively. The modulus of elasticity in bending, $\mathrm{Eb}$, is calculated from the equation:

$$
E_{b}=\frac{L^{3} * m}{4 *_{w} * t^{3}}
$$

where $\mathrm{m}$ is slope of the tangent to the initial straight-line portion of the load-deflection curve $(\mathrm{N} / \mathrm{mm})$, respectively.

\section{c) Shear test.}

The compression of double-notched specimens (DNS) is identified to determine the In-plane shear strength (IPSS) of fabricated composites. The shear test is performed according to the ASTM D3846 standard. 
$I P S S=\frac{P_{c \max }}{t * h}$

where

$P_{c}$ max is the ultimate compressive load, and $\mathrm{h}$ is the distance between the two notches, respectively.

\section{a) Impact test}

Impact strength and absorbed energy are measured by Izod test according to ASTM 256. Impact tests are carried out on impact machine type AVERY Denison. Impact strength is calculated as the energy absorbed per unit area of the fractured cross-section[12].

\section{b) Hardness Test}

Hardness test is run according to the specifications of ASTM E384 - 10. The hardness is carried out on identec hardness tester. Brinell hardness test is conducted on the manufactured sample using a standard Brinell hardness tester. A load of $250 \mathrm{~kg}$ is applied on the manufactured specimens for $30 \mathrm{sec}$ using 1/16inch diameter hard metal ball indenter. The hardness is measured at six different locations of the fabricated specimens and the average value is calculated. Hardness is calculated using the following equation [11]:

$$
B H N=\frac{2 P}{\pi D\left(D-\sqrt{D^{2}-d^{2}}\right)}
$$

where $P$ is the applied force $\left(\mathrm{Kg}_{\mathrm{f}}\right) ; D$ and $d$ are the diameter of indenter and the diameter of indentation in $\mathrm{mm}$, respectively.

\section{c) Water Absorption Test}

Water uptake tests are carried out according to ASTM D5229/D5229M - 14. Manufactured specimens are immersed in distilled water at $25^{\circ} \mathrm{C}$. Specimens are immersed up to 200 days in water. The specimens are periodically withdrawn from the water and then are wiped to remove water droplets. Thereafter the specimens are weighed with an analytical balance of up to 10-4 g accuracy to examine the mass change during the water absorption process. The water content, $\mathrm{M}(\mathrm{t})$, that is absorbed by each specimen is calculated as the mass gain percent relative to its initial weight $\left({ }^{w_{0}}\right)$ as follows [13]:

$$
M(t)=\left(\frac{w_{t}-w_{0}}{w_{0}}\right) \times 100
$$

where $w_{t}$ is the sample weight after time t.

\section{d) Morphological properties}

Microstructural investigations are performed on some of the manufactured composites by using FEI Quanta 250 FEG. Scanning electron microscope (SEM) images are used to study the interfacial bond between polyester matrix and fiber reinforcements. Also, fracture surface of the manufactured composite samples is coated to make the sample conductive. Gold coating is used for helping in improvement of image resolution.

\section{e) Density and Void content of the fabricated composites}

Void content of the fabricated composites is determined according to ASTM D2734-94 standard using the following equations:

$$
\begin{aligned}
V_{f} & =\frac{\rho_{t h}-\rho_{e x}}{\rho_{t h}} \times 100 \\
\rho_{t h} & =\rho_{m} V_{m}+\rho_{G F} V_{G F}+\rho_{R S} V_{R S} \\
\rho_{e x} & =\frac{\text { sample weigh }}{\text { Sample Volume }}
\end{aligned}
$$

where Vf is the void fraction; $\rho_{t h}$ and $\rho_{e x}$ are the theoretical and experimental density, respectively. Vm, VGF and VRS are the volume fractions of polyester matrix, glass fiber and rice straw, respectively. $\rho_{m}, \rho_{G F}$ and $\rho_{R S}$ are the densities of polyester matrix, glass fiber, rice straw, respectively.

\section{RESUlts AND Discussions}

\section{A. Tensile properties}

Figure 3 shows the highest tensile strength and strain that is obtained for GF/polyester composites. Tensile strength of composite reinforced with rice straw mat is increased over pure polyester. An increase of $4.27 \%$ in tensile strength is obtained by reinforcing polyester by the new developed ricestraw mat. However, the tensile strain of RS/polyester composites is lower than pure polyester. Reinforcing glass fiber with rice straw mat to polyester improves the tensile strength of rice straw/polyester by $85.7 \%$. Figure 4 show the specific tensile strength of fabricated specimens. The RS composite yields an improvement in specific tensile strength of $46.34 \%$ as compared to polyester. However, by hybridization of GF and RS in polyester leads to a significant enhancement of $53.49 \%$ when compared to RS/polyester composites. This high improve is attributed to the lightweight of RS fiber which is one of the main advantages of using natural fiber. Figure 5 shows the modulus of elasticity for short fiber reinforced polyester composites. The highest modulus of elasticity is obtained by chopped glass fiber composites. The composite reinforced with rice straw is increased over polyester. An increase of $64 \%$ in tensile modulus is attained by reinforcing polyester by the developed RS mat. Adding glass fiber to rice straw mat to polyester improve the modulus of elasticity of rice straw reinforced polyester by $22 \%$. This is mainly due to the higher strength and stiffness of GF in relation to rice straw and also to better adhesion with polyester. Figure 6 show the specific tensile modulus of the manufactured specimens. The figure indicates a significant increase of $100 \%$ with RS/polyester composites as compared to pure polyester. However, a slight increase is shown when RS hybridized with GF in polyester matrix. This 
is due to the low density of RS mat when compared to glass fiber reinforcement. Figure 7 shows the fracture mode after the tensile test for fiber reinforced polyester composites. Complete separation is occurred with all specimens except for hybrid GF/RS reinforced polyester composites. This indicate that adding glass fiber to RS enhance the bonding and strength of the fiber reinforcement.

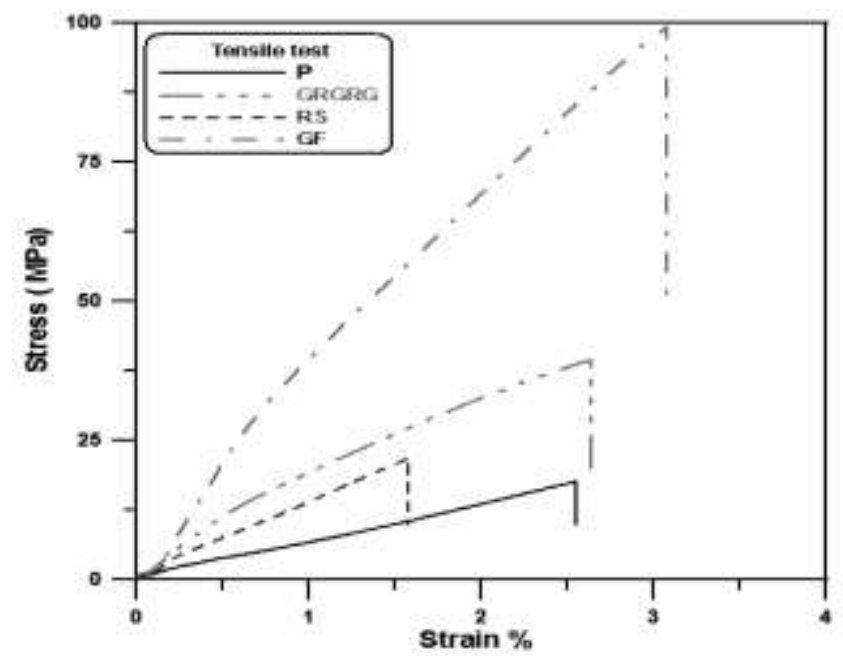

Fig. 3. Tensile stress-strain curves of the manufactured specimens.

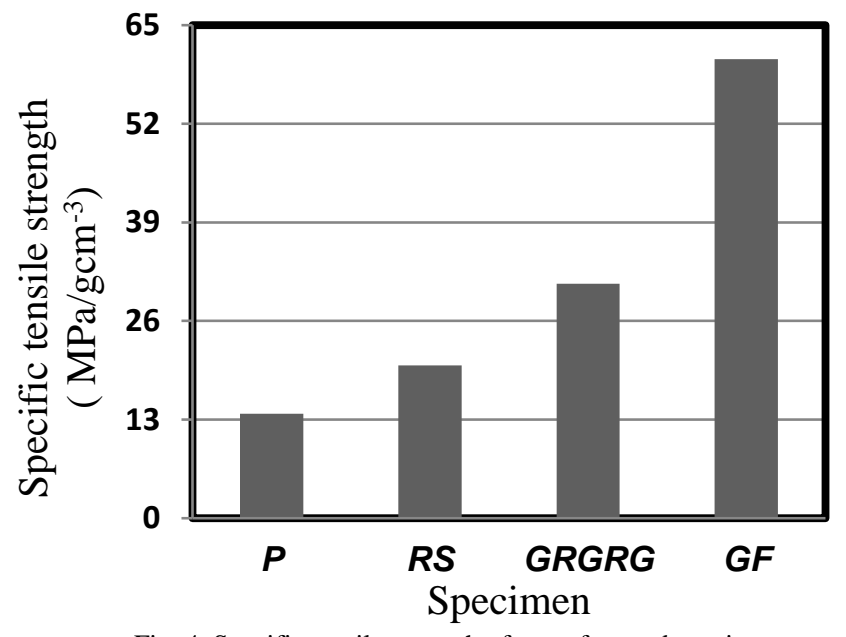

Fig. 4. Specific tensile strength of manufactured specimens.

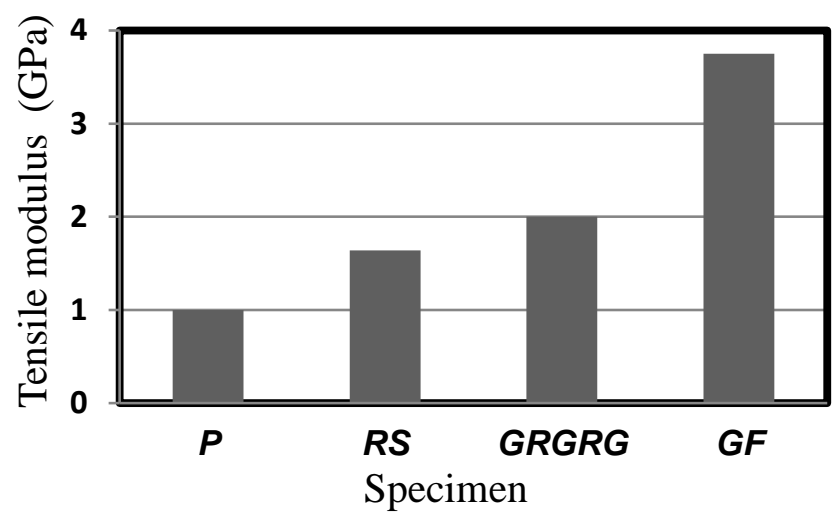

Fig. 5. Tensile modulus of the manufactured specimens.

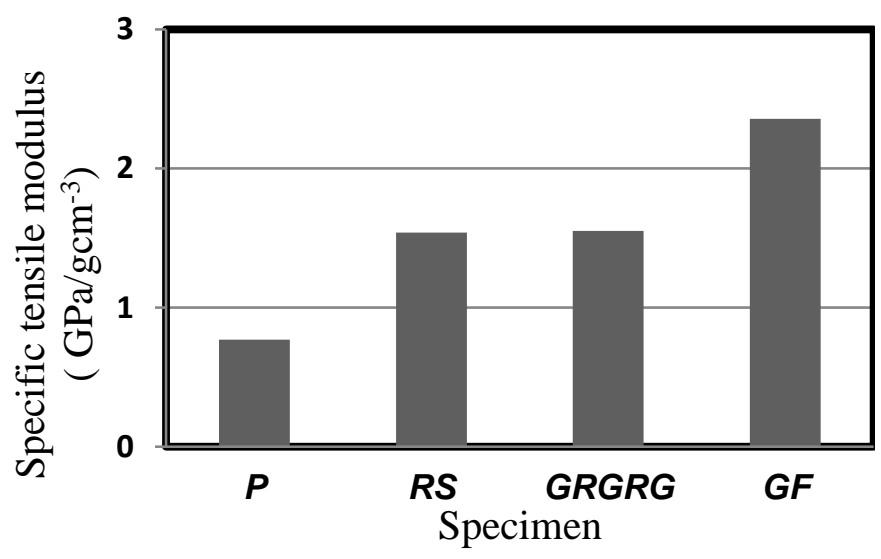

Fig. 6. Specific tensile modulus of the manufactured specimens.

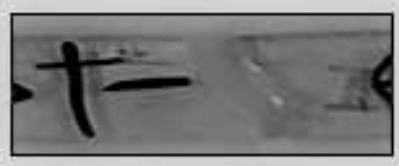

(a) $\mathrm{P}$

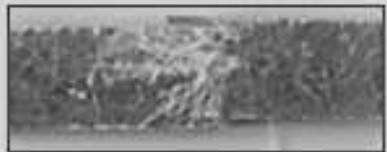

(C) GRGRG

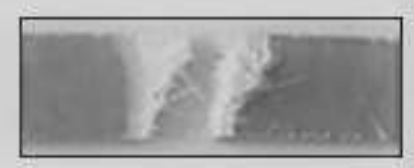

(b)GF/polyester

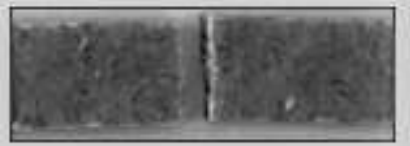

(d) RS/polyester
Fig. 7. The fracture mode after tensile test for fiber reinforced polyester composites.

\section{B. $\quad$ Flexural properties}

Figure 8 shows the flexural stress-strain curves of manufactured specimens. It is evident that pure polyester has the lower flexural strength while GF/polyester has the higher flexural strength and strain. Reinforcing polyester with developed RS mat improves the flexural strength by $65 \%$, but a slight decrease in flexural strain is observed. Hybrid composites GRGRG are found to be stronger and stiffer than RS/polyester composites. Both flexural strength and strain are 
increased by adding GF to RS reinforcement in polyester matrix. Hybridization gives an increase of $76.7 \%$ in flexural strength as compared to RS/polyester composites. Figure 9 shows the specific flexural strength of manufactured specimens. An improvement of $102.4 \%$ is achieved in specific flexural strength by reinforcing polyester by RS mats. Further improvement of $45.2 \%$ is attained with GRGRG composites as compared to RS/polyester composites.

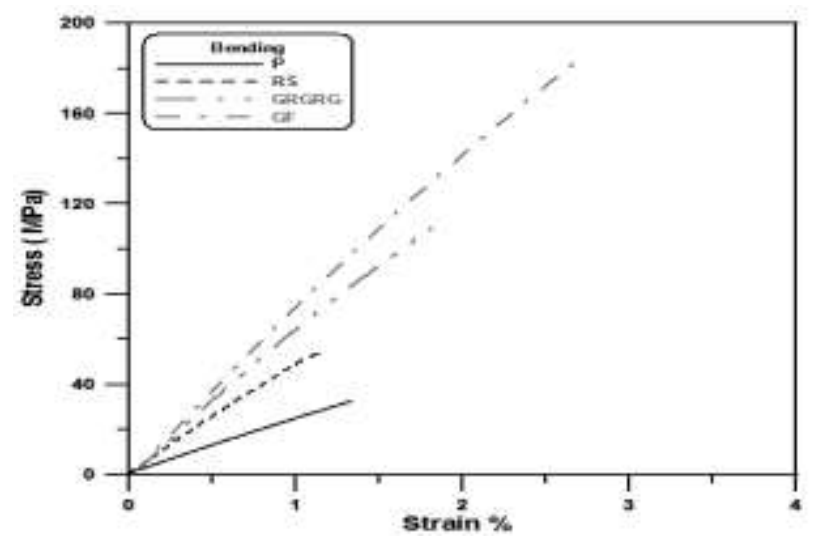

Fig. 8. Flexural stress-strain curves of the manufactured specimens.

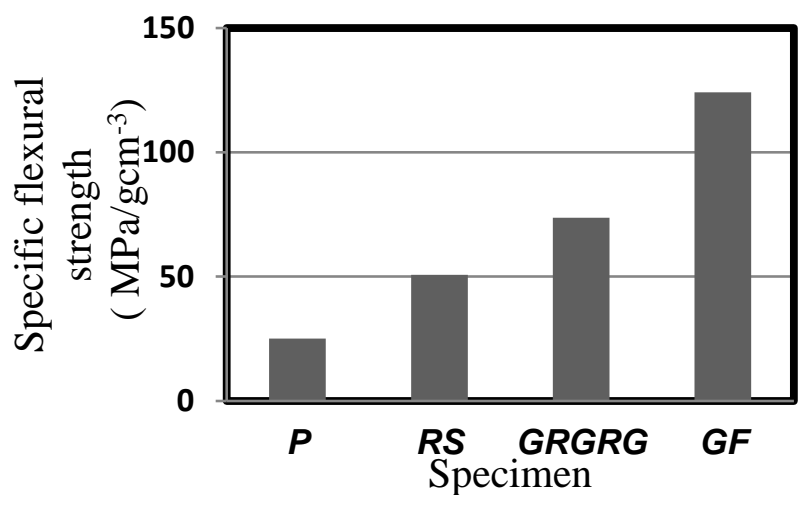

Fig. 9. Specific flexural strength of manufactured specimens.

Figure 10 shows the flexural modulus of the manufactured specimens. Flexural modulus of pure polyester is increased by $101.18 \%$ due to the reinforcement with developed RS mat. Further increase in flexural modulus of $24 \%$ is observed with GRGRG composites as compared to RS/composites. In addition, specific flexural modulus of the manufactured specimens is illustrated in Figure 11. The highest specific flexural modulus is obtained with GRGRG composites. The light weight of RS makes the specific flexural modulus higher than that obtained with GF/polyester composites. A significant improvement of $146.7 \%$ is observed with RS/polyester composites as compared with pure polyester.A slight improvement of $1.94 \%$ is attained with GRGRG composites as compared RS/composites. Figure 12 shows the failure of 3point flexural specimens where the failure occurred at the mid span of the test specimen.

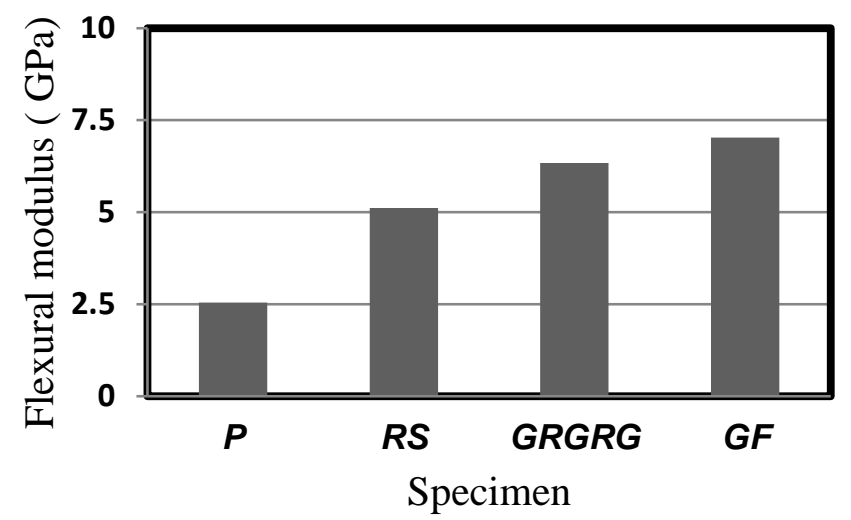

Fig. 10. Flexural modulus of the manufactured specimens.

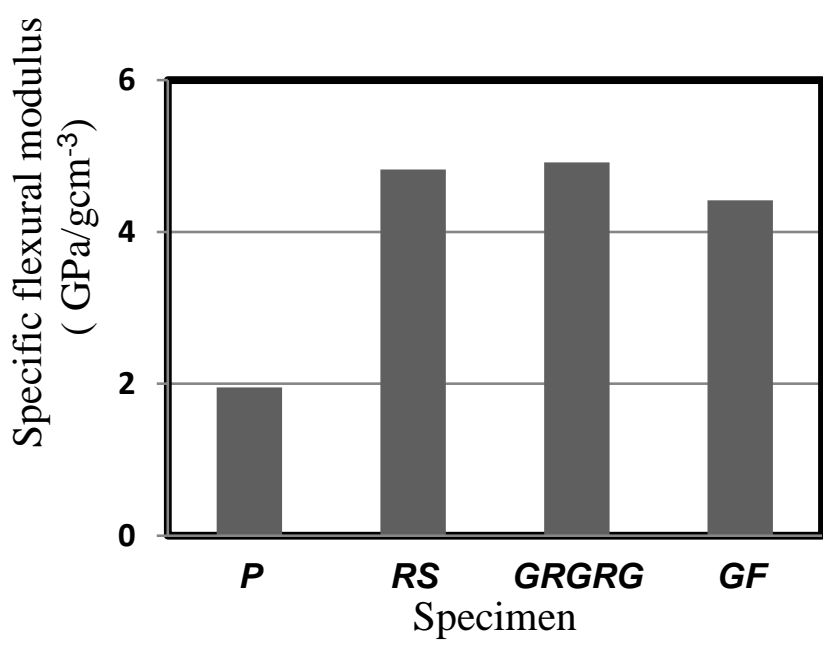

Fig. 11. Specific flexural modulus of the manufactured specimens.

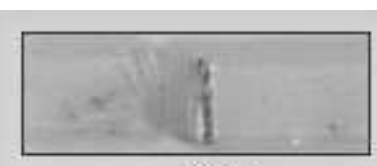

(a) $\mathrm{P}$

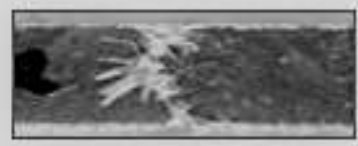

(c) GRGRG

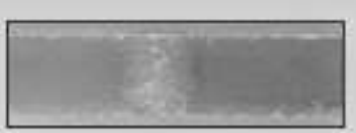

(b)GF/polyester

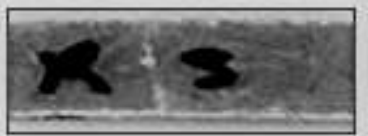

(d) RS/polyester
Fig. 12. The fracture mode after bending test for fiber reinforced polyester composites.

After bending test, pure polyester broken and separated as it behaves as a brittle material. However, no complete separation is occurred with other composites. Erratic crack is initiated on the compression side of the mid-span of the specimen. In the region of highest flexural stress, delamination of fibers occurred between the inner loading points. 


\section{Shear Behavior}

Polyester is a brittle material compared to rice straw. Figure 13 shows the shear strength of the manufactured composites. The incorporation of RS in polyester results in an increase in the shear strength by $113.9 \%$ as compared to polyester. By adding glass fiber to RS, the shear strength is improved significantly by $77.11 \%$ as compared with the RS composite. Similar results were obtained by [14]. The shear strength of the palymra/glass fiber/polyester hybrid composites is higher than the palymra /polyester composites. So, hybridization with synthetic fiber reinforcement is considered a viable method for enhancing the durability and mechanical properties of natural fiber reinforcement composites.

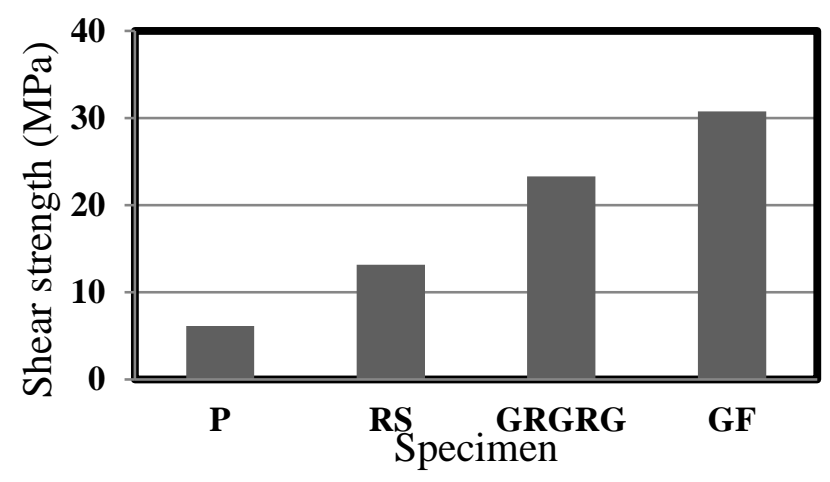

Fig. 13. Shear behavior of the manufactured specimens.

\section{Impact strength}

Figure 14 shows that pure polyester elucidates very low impact strength. However, impact strength of the glass fiber/polyester composites is higher than that of polyester as well as rice straw/polyester composites.

Addition of RS fiber increases the impact strength by $43 \%$ over pure P. Further increase in the impact strength is attained by the addition of glass fibers to RS fiber.

Impact strength of RS/glass fiber composite is increased by $35.9 \%$ over pure $\mathrm{P}$. This may be due to the improved resistance obtained by glass fibers. Hybridization between RS and glass fiber is used to improve their impact strength. The rice straw is frequently fractured due to its wear molecular bonding. But when adding glass fiber with RS, the fracture is holed without separation, so the properties are improved. Similar results obtained by [15] were indicated that the E-glass fiber/ polyester composites had the highest impact resistance. Incorporating of high impact resistant fabrics in the outer layers of the manufactured composites, higher impact values can be achieved.

\section{E. Hardness}

The hardness of fiber reinforced composites is higher than that of pure polyester as shown in Figure 15. Reinforcing polyester with RS mats results in improvement of hardness by $43.7 \%$. Hybridization of glass fiber and rice straw to polyester improve the hardness of single rice straw mat reinforced polyester by $82.6 \%$. Hybrid composite GRGRG has intermediate hardness value between RS/polyester and GF/composites.

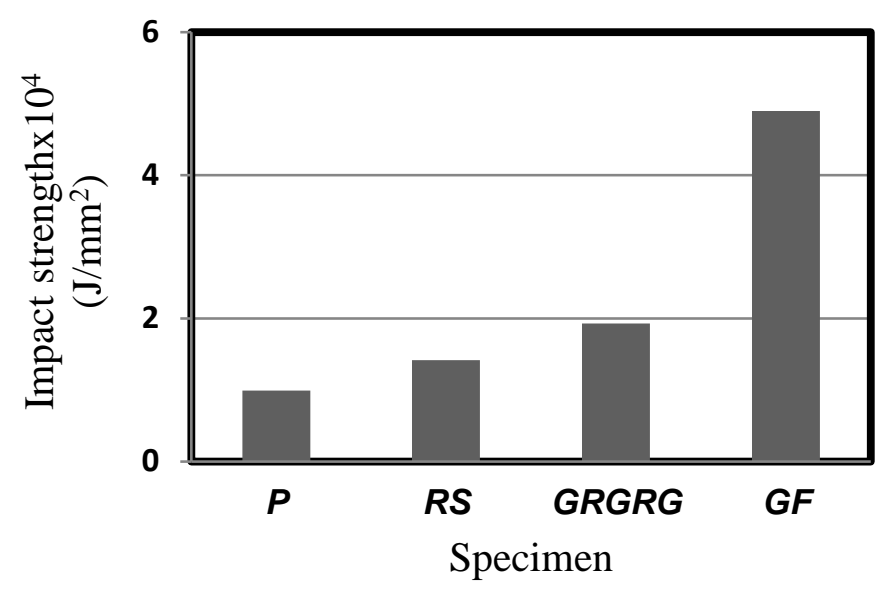

Fig. 14. Impact behavior of the manufactured specimens.

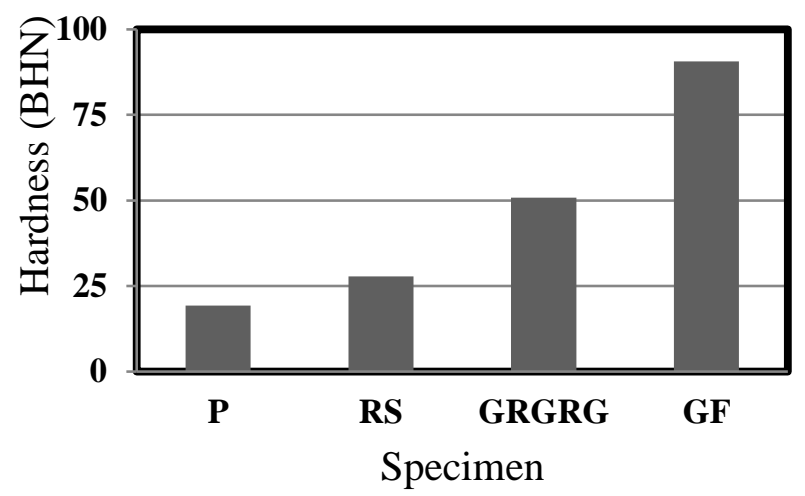

Fig. 15. Hardness of the manufactured specimens.

\section{F. $\quad$ Density and Void content}

Trapped air or other volatiles may be contained during the manufacturing of fiber reinforced composites. The most common cause of voids is the incapability of the matrix to displace internal air in fibers during impregnation [16]. Table 3 shows the values of the theoretical and experimental density and the void content of the fabricated composites. Void content has lowest value with RS/polyester composites. Good fiber dispersion of RS leads to good interfacial bonding, therefore reducing voids by ensuring that fibers are completely surrounded by the matrix. However, void content increases with combination GF with RS reinforcement in polyester matrix. Glass fiber/polyester composites have the highest void content.

\section{G. Water absorption behavior}

All cellulosic fibers are hydrophilic in nature absorb moisture from environment until equilibrium is attained. Moisture absorption causes dimensional variations in the fiber either natural or synthetic as well as composite materials, 
hence affecting the interface and the mechanical properties of composites. Moisture may lead to poor fiber-matrix interface.

\begin{tabular}{c||c||c||c}
$\begin{array}{c}\text { Type of } \\
\text { composites }\end{array}$ & $\begin{array}{c}\text { Theoretical } \\
\text { density } \\
\left(\mathbf{g} / \mathbf{c m}^{\mathbf{3}}\right)\end{array}$ & $\begin{array}{c}\text { Experimental } \\
\text { density } \\
\left(\mathbf{g} / \mathbf{c m}^{\mathbf{3}}\right)\end{array}$ & $\begin{array}{c}\text { Void } \\
\text { content } \\
(\mathbf{\%})\end{array}$ \\
\hline$R S$ & 1.08 & 1.06 & 1.55 \\
\hline$G R G R G$ & 1.29 & 1.25 & 3.49 \\
\hline$G F$ & 1.53 & 1.44 & 6.25
\end{tabular}

TABL3.

DENSITY AND VOID CONTENT OF THE FABRICATED COMPOSITES.

Therefore transfer of load will be bad due to poor interface and the composite material will deteriorate [17]. The influence of water immersion on the durability of manufactured composite specimen is experimentally investigated. Figure 16 shows the water absorption content of the manufactured composites. The water uptake content increases as the immersion time increases. Highest water absorption is observed for composites reinforced with rice straw mat. Also, it is observed that the water absorption of glass fiber reinforced polyester is lower than the other specimens. However, hybrid GRGRG composite has lower water absorption content than RS/polyester composites. Thus, for improving the durability of fiber reinforced composites, it is important to decrease the water absorption by providing the synthetic fiber as an outer layer on both sides of the manufactured composites. This attributed to the presence of synthetic fiber layers which are directly in contact with low water absorption content compared with natural fibers[18]. Similar results was observed by Velmurugan and Manikandan [14]. It is demonstrated that environmental resistance of palmyra fiber composite can be improved by incorporation of glass fiber. The composites which have good interfacial properties can be exposed to a different range of environmental conditioning. Otherwise, if fiber composites have poor interface, then environments degrade fiber/matrix interfacial bond and leads in the loss of microstructural integrity [7]. This weak bond leads to absorb more water and this may be a cause for increasing the water absorption of rice straw mat.

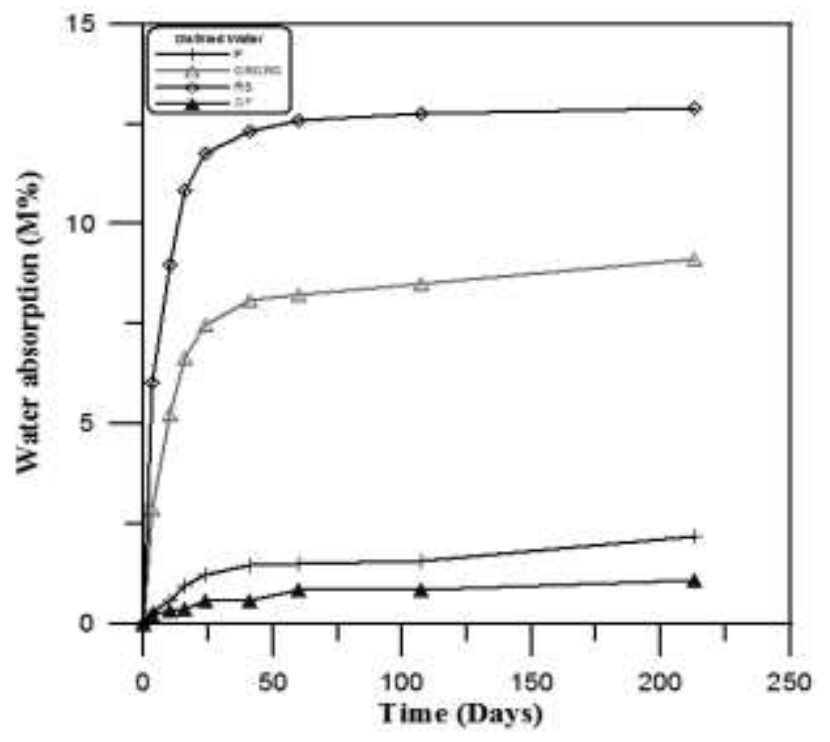

Fig. 16. Water absorption of the manufactured specimens.

\section{H. $\quad$ Fracture surface morphology}

The properties and performance of manufactured composites can be controlled by the fiber-matrix interface. Good interfacial properties are essential to ensure efficient load transmission from matrix to reinforcement which leads to reduce stress absorption and improves overall mechanical properties. The strength of fiber reinforced composites depends not only on the substrate but also on interface strength. Figure 17 a shows SEM of tensile fractured surface of rice straw reinforced polyester composites. Poor interfacial bond between rice straw fiber/polyester is observed. The weak bond is the main reason for lowering the tensile strength and modulus. Rice straw pulls out as well as holes result from fiber delamination are observed regardless nature of the fiber. This indicates that lignocellulosic RS fibers are hardly wetted by a polyester matrix with a gap developing around the fibers. Pulled-out fibers and gaps are commonly observed when adhesion between fibers and matrix is not sufficient [19]. In contrary, good bonding between GF with RS with polyester matrix is clear from Fig. 17(b). The penetration of polyester into types of reinforcement improves the fiber and matrix adhesion. In addition, the interaction between GF and RS is good. This reveals the good tensile properties of hybrid GRGRG composites. Figure 18 shows SEM for the flexural fractured surface of RS/polyester composites. Fracture mechanisms like fiber pull-out and fiber breakage are evident from the Figure. In addition, matrix fracture is occurred as the composite is subjected to flexural load. Figure 19 shows SEM for the fractured surface of RS/polyester composites under shear loading. Fiber breakage, matrix cracking and fibermatrix debonding are clearly observed as a cause of shear loading applied to RS composite. Debonding occurs if the shear transferred to fiber reinforcement exceeds the interfacial adhesion strength between the matrix and the fiber. This can be due to poor interfacial bond between fiber and polymeric matrix. Figure 20 (a) shows SEM for the fractured surface of 
RS/polyester composites after impact loading. Fiber and matrix breakage are evident in RS composites. However, good interfacial region is occurred between GF and RS fiber as shown in Figure 20 (b). This leads to an improvement in the ability of fiber reinforced composite to absorb energy during crack propagation thus enhance the impact strength of the manufactured composites.

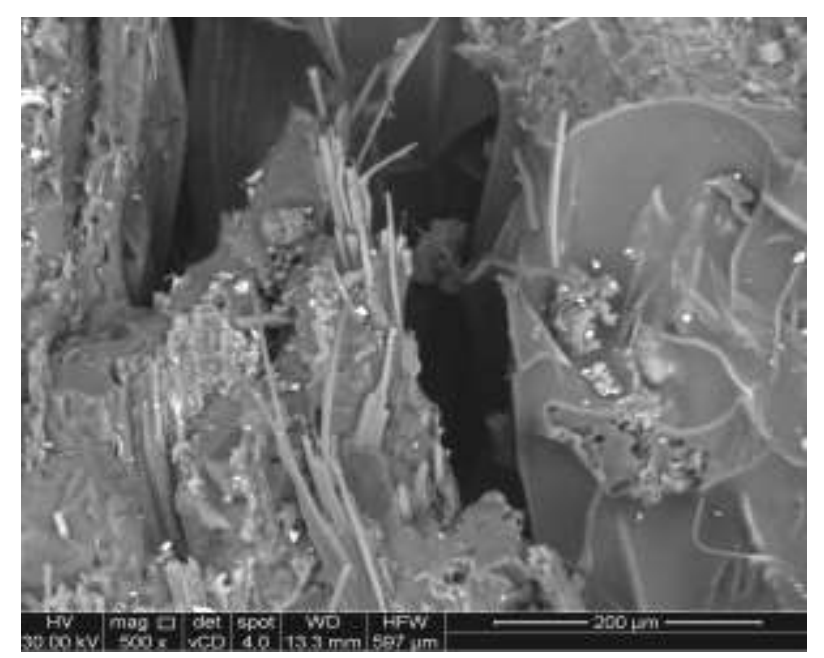

(a)

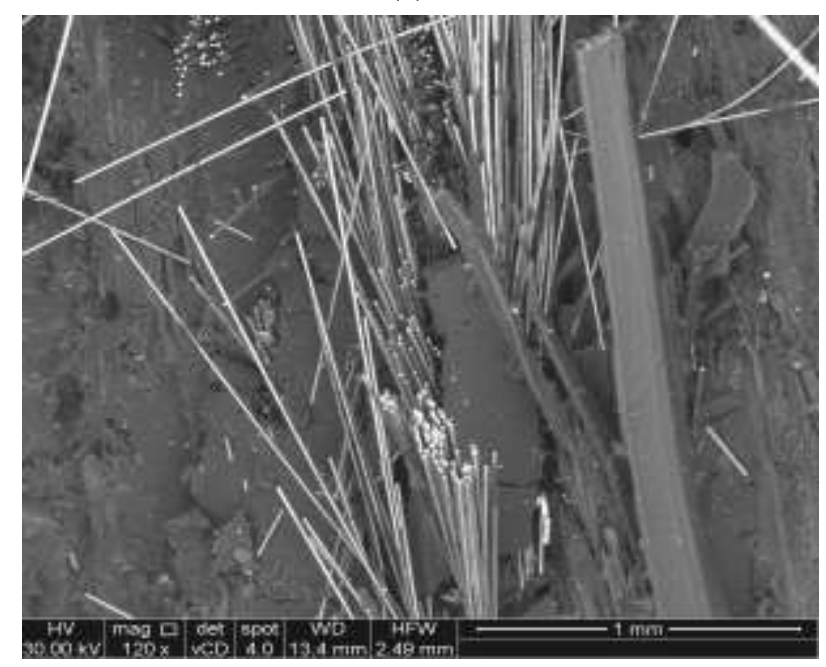

(b)

Fig. 17. SEM of the tensile fractured surface for (a) RS/polyester composites; (b) hybrid GF/RS/polvester composites.

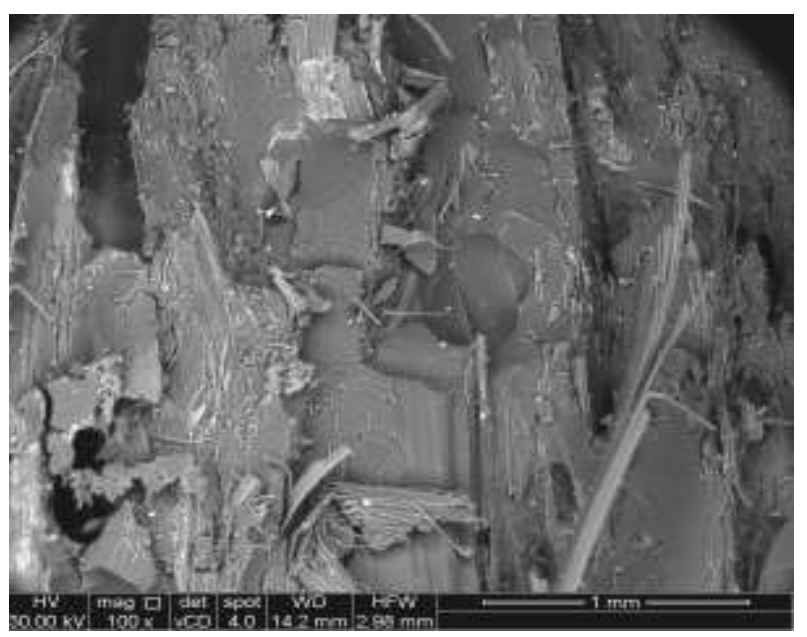

Fig.18. SEM of flexural fractured surface of RS/polyester composites.

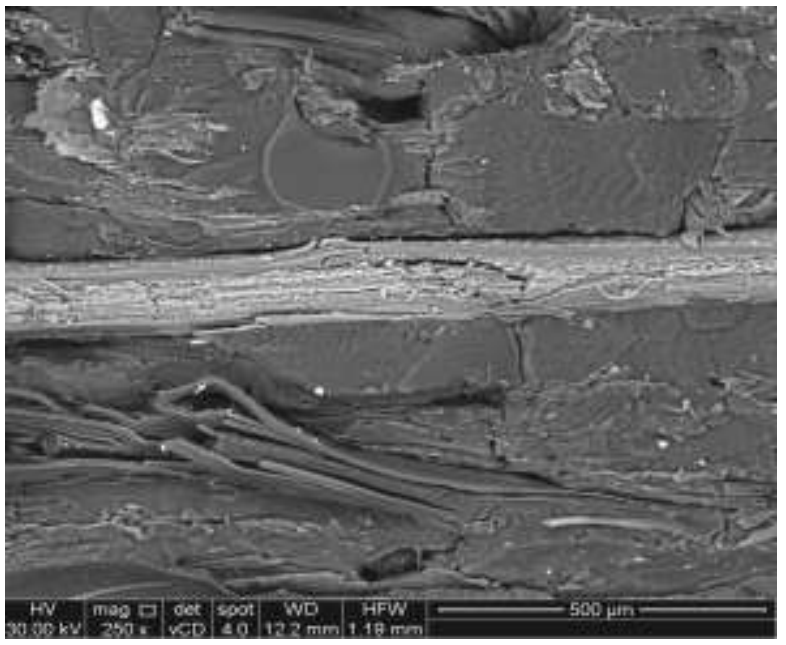

Fig. 19. SEM of fractured surface of RS/polyester composites under shear loading.

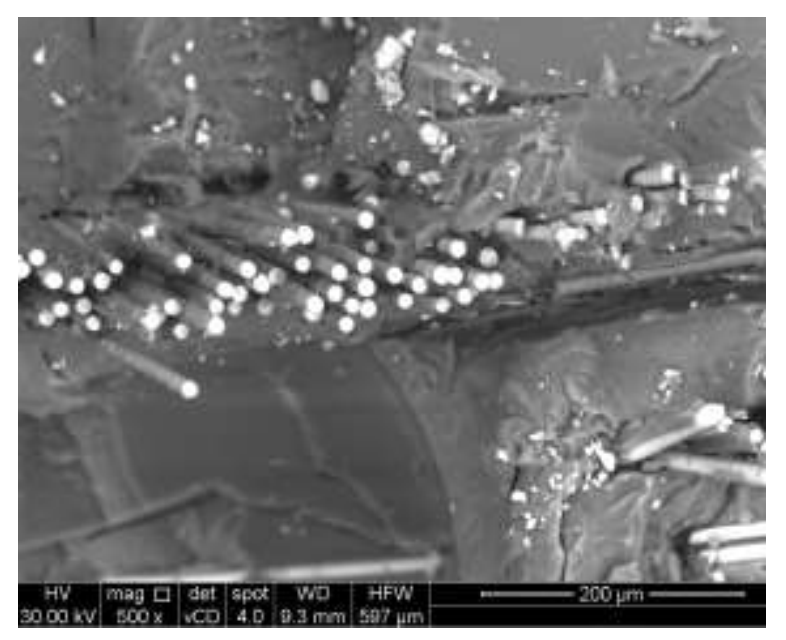

(a)

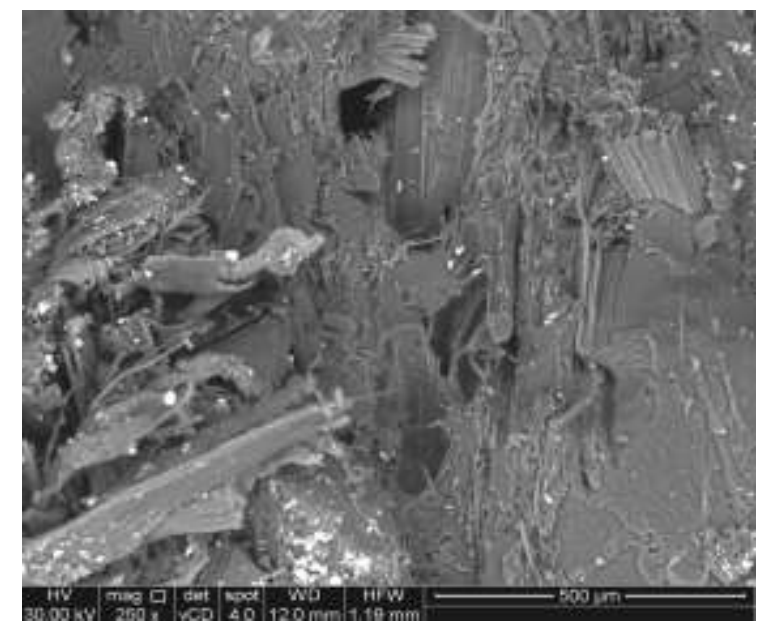

(b)

Fig. 20. SEM of fractured surface after impact loading for (a) RS/polyester composites;(b) Hybrid GF/RS/polyester composites. 


\section{CONCLUSIONS}

Successful fabrication of the new random oriented rice straw mat fiber_reinforced polyester composites are studied. Reinforcing polyester by this new rice straw mat has better tensile, bending, shear, impact and hardness properties as compared with pure polyester. Hybridization of glass fiber with rice straw mat reinforced polyester improves the mechanical properties over pure polyester and rise straw/polyester composites. The mechanical properties of glass fiber/polyester composites are higher than other specimens except for specific flexural modulus; hybrid composites are considered the best specimen. Glassfiber/polyester is mixing with natural fibers to increase engineering applications. A balance in cost and performance could be achieved through hybridization.

\section{References}

[1] M. Jawaid, O. Y. Alothman, M. T. Paridah, and H. P. S. A. Khalil, "Effect of Oil Palm and Jute Fiber Treatment on Mechanical Performance of Epoxy Hybrid Composites," Int. J. Polym. Anal. Charact., vol. 19, no. 1, pp. 62-69, 2014.

[2] M. S. Sreekala, J. George, M. G. Kumaran, and S. Thomas, "The mechanical performance of hybrid phenol-formaldehyde-based composites reinforced with glass and oil palm fibres," Compos. Sci. Technol., vol. 62, no. 3, pp. 339-353, 2002.

[3] K. Jarukumjorn and N. Suppakarn, "Composites: Part B Effect of glass fiber hybridization on properties of sisal fiber polypropylene composites," Compos. Part B, vol. 40, no. 7, pp. 623-627, 2009.

[4] S. Panthapulakkal and M. Sain, "Injection-Molded Short Hemp Fiber / Glass Fiber- Reinforced Polypropylene Hybrid Composites - Mechanical, Water Absorption and Thermal Properties," Appl. Polym. Sci., vol. 103, pp. 2432-2441, 2006.

[5] K. P. Ashik, R. S. Sharma, and V. L. J. Guptha, "ScienceDirect Investigation of moisture absorption and mechanical properties of natural / glass fiber reinforced polymer hybrid composites," Mater. Today Proc., vol. 5, no. 1, pp. 3000-3007, 2018.

[6] S. B. Eskander, M. E. Tawfik, and M. L. Tawfic, "Mechanical, flammability and thermal degradation characteristics of rice straw fiber-recycled polystyrene foam hard wood composites incorporating fire retardants," J. Therm. Anal. Calorim., vol. 132, no. 2, pp. 1115-1124, 2018.

[7] A. Ali et al., "Hydrophobic treatment of natural fibers and their composites-A review," J. Ind. Text., vol. 47, no. 8, pp. 21532183, 2018.

[8] A. V. Ratna Prasad, K. Murali Mohan Rao, M. Anil Kumar, and K. Mohan Rao, "Flexural properties of rice straw reinforced polyester composites," Indian J. Fibre Text. Res., vol. 31, no. 2, pp. 335-338, 2006.

[9] M. C. S. Moreno and J. J. L. Cela, "Failure envelope under biaxial tensile loading for chopped glass-reinforced polyester composites," Compos. Sci. Technol., vol. 72, no. 1, pp. 91-96, 2011.

[10] M. R. Sanjay, G. R. Arpitha, and B. Yogesha, "Study on Mechanical Properties of Natural - Glass Fibre Reinforced Polymer Hybrid Composites: A Review," Mater. Today Proc., vol. 2, no. 4-5, pp. 2959-2967, 2015.

[11] M. S. EL-Wazery, M. I. EL-Elamy, and S. H. Zoalfakar, "Mechanical Properties of Glass Fiber Reinforced Polyester Composites," Int. J. Adv. Eng. Technol., vol. 14, no. 3, pp. 121131, 2017.

[12] M. Megahed, A. A. Megahed, and M. A. Agwa, "The influence of incorporation of silica and carbon nanoparticles on the mechanical properties of hybrid glass fiber reinforced epoxy," J. Ind. Text., vol. 49, no. 2, pp. 181-199, 2019.

[13] A. A. E. W. Megahed and M. Megahed, "Fabrication and characterization of functionally graded nanoclay/glass fiber/epoxy hybrid nanocomposite laminates," Iran. Polym. J. (English Ed., vol. 26, no. 9, pp. 673-680, 2017.
[14] R. Velmurugan and V. Manikandan, "Mechanical properties of palmyra / glass fiber hybrid composites," Compos. Part A, vol. 38, pp. 2216-2226, 2007.

[15] H. Sezgin and O. B. Berkalp, "The effect of hybridization on significant characteristics of jute / glass and jute / carbonreinforced composites," Ind. Text., vol. 47, pp. 283-296, 2017.

[16] M. Abd El-baky, "Experimental investigation on impact performance of glass-polypropylene hybrid composites," J. Thermoplast. Compos. Mater., p. 089270571877287, 2018.

[17] B. Wang, S. Panigrahi, L. Tabil, and W. Crerar, "Pre-treatment of flax fibers for use in rotationally molded biocomposites," J. Reinf. Plast. Compos., vol. 26, no. 5, pp. 447-463, 2007.

[18] K. Mayandi, N. Rajini, M. Manojprabhakar, S. Siengchin, and N. Ayrilmis, 1 - Recent studies on durability of natural/synthetic fiber reinforced hybrid polymer composites. Elsevier Ltd, 2019.

[19] [Y. Habibi, W. K. El-zawawy, M. M. Ibrahim, and A. Dufresne, "Processing and characterization of reinforced polyethylene composites made with lignocellulosic fibers from Egyptian agroindustrial residues," Compos. Sci. Technol., vol. 68, pp. 1877$1885,2008$.

[20] S. Panthapulakkal and M. Sain, "Injection-Molded Short Hemp Fiber / Glass Fiber- Reinforced Polypropylene Hybrid Composites - Mechanical, Water Absorption and Thermal Properties," J. Appl. Polym. Sci., vol. 103, pp. 2432-2441, 2006.

[21] K. P. Ashik, R. S. Sharma, and V. L. J. Guptha, "Investigation of moisture absorption and mechanical properties of natural / glass fiber reinforced polymer hybrid composites," Mater. Today Proc., vol. 5, no. 1, pp. 3000-3007, 2018.

[22] M. M. Thwe and K. Liao, "Effects of environmental aging on the mechanical properties of bamboo -glass fiber reinforced polymer matrix hybrid composites," Compos. Part A, vol. 33, pp. 43-52, 2002.

[23] M. M. Davoodi, S. M. Sapuan, D. Ahmad, A. Ali, A. Khalina, and M. Jonoobi, "Mechanical properties of hybrid kenaf / glass reinforced epoxy composite for passenger car bumper beam," Mater. Des., vol. 31, no. 10, pp. 4927-4932, 2010.

[24] R. Velmurugan and V. Manikandan, "Mechanical properties of palmyra/glass fiber hybrid composites," Compos. Part A Appl. Sci. Manuf., vol. 38, no. 10, pp. 2216-2226, 2007.

[25] K. L. Pickering, M. G. A. Efendy, and T. M. Le, "A review of recent developments in natural fibre composites and their mechanical performance," Compos. Part A Appl. Sci. Manuf., vol. 83, no. September, pp. 98-112, 2016.

[26] S. B. Eskander, M. E. Tawfik, and M. L. Tawfic, "Mechanical, flammability and thermal degradation characteristics of rice straw fiber-recycled polystyrene foam hard wood composites incorporating fire retardants," J. Therm. Anal. Calorim., vol. 132, no. 2, pp. 1115-1124, 2018.

[27] M. S. EL-Wazery, M. I. EL-Elamy, and S. H. Zoalfakar, "Mechanical properties of glass fiber reinforced polyester composites,” Int. J. Appl. Sci. Eng., vol. 14, no. 3, pp. 121-131, 2017.

[28] M. Megahed, A. A. Megahed, and M. A. Agwa, "The influence of incorporation of silica and carbon nanoparticles on the mechanical properties of hybrid glass fiber reinforced epoxy," J. Ind. Text., 2018.

[29] A. A. E. W. Megahed and M. Megahed, "Fabrication and characterization of functionally graded nanoclay/glass fiber/epoxy hybrid nanocomposite laminates," Iran. Polym. J. (English Ed., vol. 26, no. 9, pp. 673-680, 2017.

[30] H. Sezgin and O. B. Berkalp, "The effect of hybridization on significant characteristics of jute / glass and jute / carbonreinforced composites," 2017.

[31] M. Abd El-baky, "Experimental investigation on impact performance of glass-polypropylene hybrid composites," J. Thermoplast. Compos. Mater., p. 089270571877287, 2018.

[32] B. Wang, S. Panigrahi, L. Tabil, and W. Crerar, "Pre-treatment of flax fibers for use in rotationally molded biocomposites," J. Reinf. Plast. Compos., vol. 26, no. 5, pp. 447-463, 2007.

[33] K. Mayandi, N. Rajini, M. Manojprabhakar, S. Siengchin, and N. Ayrilmis, Recent studies on durability of natural/synthetic fiber reinforced hybrid polymer composites., 2019. 